\title{
Las nuevas relaciones institucionales de las Diputaciones en Andalucía: Los Días de la Provincia.
}

\section{The new institutional relations of the Provincial Councils in Andalusia: The Days of the Province.}

\author{
Margarita Parrilla Amador ${ }^{1}$ \\ margaritaparrilla@yahoo.com \\ Recepción: 27/04/18 Revisión: 01/07/18 Aceptación: 01/07/18 Publicación: 05/07/18
}

\section{Resumen}

Las nuevas formas de relación que se están surgiendo entre la administración y los ciudadanos están presentes también en el ámbito del protocolo. La celebración de los "Día de la Provincia", que surgen como conmemoración de un acontecimiento histórico, está dando lugar a una política de relaciones institucionales. La solemnidad de la efeméride busca afianzar su existencia mediante la participación de la sociedad a través de actos colectivos como son, por ejemplo, la entrega de honores y distinciones. Un ejemplo de ello son las diputaciones provinciales de Andalucía y como han organizado, en cada caso, sus correspondientes días de la provincia.

Palabras claves: Protocolo, Relaciones Institucionales, Honores, Distinciones, Diputación Provincial.

\section{Abstract}

The new forms of relationship that are emerging between the administration and the citizens are also present in the scope of the protocol. The celebration of the "Day of the Province", which arise as a commemoration of a historical event, is giving rise to a policy of institutional relations. The solemnity of the event seeks to strengthen its existence through the participation of society through collective acts such as, for example, the delivery of honors and distinctions. Examples of this are the provincial councils of Andalusia and how they have organized, in each case, their corresponding days of the province.

Keywords: Protocol, Institutional Relation, Honors, Accolades, County council.

\footnotetext{
${ }^{1}$ Doctora en Historia por la Universidad de Sevilla.
} 


\section{Sumario}

1. Introducción

2. Método

3. Resultados

4. Discusión

5. Referencias

\section{INTRODUCCIÓN}

El momento de cambio que ha supuesto la globalización y la situación de descrédito de las instituciones públicas hace que sea perentorio para éstas retomar este vínculo con la sociedad y a los investigadores nos motivan a enseñar cómo han sido estas relaciones en el pasado, cuál es la situación actual en la que se encuentran y poder anticipar su evolución en un futuro cercano.

Tomando como punto de partida las nuevas realidades sociales, culturales y comunicativas vemos que existen hoy en día nuevos formas de interactuar y, por tanto, nuevos modos de concebir la relación entre los ciudadanos y las instituciones. Gracias a la tecnología, los actos promovidos por las administraciones consiguen una mayor visibilidad y difusión que trasciende el propio ámbito territorial de aquellas.

Sin embargo hay que contextualizar el surgimiento de las Diputaciones provinciales por cuanto se erigen como la primera institución supramunicipal que utiliza la celebración de los "Días de la Provincia" como instrumento para acercar esta corporación local a la ciudadanía.

\subsection{Antecedentes}

Generalmente la aparición de una institución jurídica no se produce ex novo por voluntad exclusiva del legislador, sino que existían de antemano toda una serie de mecanismos corporativos cuya actuación previa inciden sobre la institución en ciernes, condicionándola en su formación y estableciéndose en el antecedente más inmediato de la misma (Santana, 1989, p. 75).

De una manera simbólica, lo que se entiende históricamente con el término "provincia" lo encontramos en el artículo publicado por Martínez Díez (1981). A su juicio, la primera vez que encontramos el término "provincia" para designar unas circunscripciones territoriales en el reino de Castilla sería en 1371 en las Cortes celebradas en Toro que se reiterará en 1390 en las Cortes de Segovia, aunque se entendía por "provincia" las grandes divisiones regionales del Reino. 
Durante el siglo XVI (1591) se realizó un censo acerca de las vecindades o número de vecinos de cada villa o jurisdicción del mismo. Como resultado se dividió el Reino en 32 provincias nominales y otras ocho circunscripciones que dan lugar a 40 demarcaciones cuyo alcance fue estrictamente fiscal. El criterio seguido para tal segmentación fue la distribución entre las 18 ciudades con derecho a voto en las Cortes ${ }^{2}$.

No será hasta la guerra de Sucesión y con la llegada de la nueva dinastía de Borbón, cuando los elementos característicos del Estado se empiecen a dar en España, si bien con una enorme debilidad. Sería con los Decretos de Nueva Planta de Felipe V, tal y como declara González Casanovas (1986, p. 19), el momento en el que los famosos Intendentes fueron unos adelantados de los ulteriores subdelegados de Fomento en las Provincias creadas por Javier de Burgos.

Para Martínez Díez (1981, p. 553) un primer punto de referencia fue la fecha del 22 de marzo de 1785 cuando el Conde de Floridablanca solicitó a los intendentes una relación de las jurisdicciones inferiores y lugares de su intendencia; con los datos de estos informes se publicaría en 1789 el siguiente título España dividida en provincias e intendencias y subdividida en partidos, corregimientos, alcaldías mayores, gobiernos políticos y militares, así realengos como de órdenes, abadengo y señorío que presentaría a España dividida en 38 provincias $^{3}$.

En la España del siglo XVIII, la división provincial responde al poder superior de la autoridad regia, militar, económica, administrativa y judicial, pero carece de una estructura uniforme y fija. Considerada por González Casanovas (1986, p. 22) como una superestructura, embrión de la futura Administración estatal, que cubrieron una red de poderes diversos, ya sea por el carácter de sus poseedores (tierras de realengo, de señorío nobiliario o eclesiástico), ya fuera por la disparidad de funciones (gubernativas, fiscales, jurisdiccionales).

\footnotetext{
${ }^{2}$ La ciudades con derecho a voto y sus provincias correspondientes son las siguientes: Burgos (Provincia de Burgos, Provincia de Trasmiera y Provincia del Condestable), Soria (Provincia de Soria), Valladolid (Provincia de Valladolid y Provincia de las Tierras del Conde de Benavente), León (Provincia de León, Provincia de Asturias de Oviedo y Provincia de Ponferrada), Zamora (Obispado de Lugo, Provincia de La Coruña y Betanzos, Provincia de Orense, Provincia de Mondoñedo, Provincia de Santiago de Compostela, Provincia de Tuy y Provincia de Zamora), Toro (Provincia de Toro y Provincia de Palencia), Salamanca (Provincia de Salamanca), Ávila (Provincia de Ávila), Segovia (Provincia de Segovia), Guadalajara (Provincia de Guadalajara), Madrid (Provincia de Madrid), Toledo (Provincia de Toledo, Ciudad Real, Campo de Calatrava, Provincia de Castilla de la Orden de Santiago, Alcaraz y su Partido y Provincia de Castilla del Campo de Montiel), Murcia (Murcia y Provincia de Murcia), Cuenca (Provincia de Cuenca y Provincia de Huete), Sevilla (Provincia de Trujillo, Provincia de León de la Orden de Santiago y Provincia de Sevilla), Córdoba (Provincia de Córdoba), Jaén (Provincia de Jaén y Calatrava del Andalucía) y Granada (Reino de Granada). Martínez Díez, 1981, p. 537.

3 Ávila, Aragón, Burgos, Gran Canaria, Cataluña, Córdoba, Cuenca, Extremadura, Betanzos, La Coruña, Santiago, Lugo, Orense, Mondoñedo, Tuy, Granada, Guadalajara, Islas Baleares, Jaén, León con Ponferrada y Asturias, Madrid, La Mancha, Murcia, Navarra, Palencia, Salamanca, Sevilla, Segovia, Soria, Toledo, Toro, Valladolid, Valencia, Álava, Vizcaya, Guipúzcoa, Zamora y Nuevas Poblaciones de Sierra Morena y Andalucía.
} 
Tampoco se eliminaron todos los poderes autónomos de los antiguos Reinos de forma inmediata, sino que se mantuvieron la heterogeneidad de múltiples privilegios personales y regionales, mientras se iba creando entidades propias e instancias administrativas.

\subsection{Orígenes de las Diputaciones Provinciales de Andalucía}

\subsubsection{Diputación de Almería}

La idea de crear una nueva provincia en la mitad oriental de Granada aparece por primera vez en el plan de organización territorial de Bauzá de 1813, que propuso la instauración de una gobernación subalterna con capital en Guadix. Si bien esta demarcación fue retrocediendo paulatinamente hacia el Este en sucesivas versiones de la división provincial, de acuerdo con el traslado de la capitalidad (Burgeño, 1995, p. 43).

Institucionalmente, los documentos acerca de la constitución de la primera Diputación de Almería que se conservan en el Archivo provincial tienen la fecha del 15 de noviembre de $1835^{4}$ en que se reunió, bajo la presidencia de D. Joaquín de Vilches (Gobernador Civil) con el fin de realizar el "nombramiento de la comisión para el examen de los documentos de elección presentados por los señores Diputados" y así ha continuado hasta nuestros días.

\subsubsection{Diputación de Cádiz.}

La fundación de la provincia gaditana vino acompañado de la creación del Consulado Marítimo de Sanlúcar de Barrameda aunque no tuvo una vida efectiva tal y como recogen Ojeda (1986, p. 156) y Burgeño (1995, p. 40). No será hasta el 16 de septiembre de 1813 cuando se produzca su definitiva instalación, de acuerdo con el decreto de 23 de mayo de 1812 y conforme a los artículos 326 y 329 de la Constitución de 1812. Siendo reconocida como provincia marítima. Mediante Real Decreto de 22 de marzo de 1820, comunicado el 25 de abril se adoptó que la provincia marítima de Cádiz se comprenda en el número de las que deben tener Diputación Provincial.

Sin embargo, durante la primera mitad del siglo XIX, las diputaciones viven la inestabilidad que sacude al nuevo régimen liberal y estarán sujetas a los vaivenes políticos del momento. Desaparece en mayo de 1814 y reaparece el 1 de mayo de $1820^{5}$, como nos informa Sanjuán Andrés (2012, p. 281) y permanecerá durante todo el Trienio Liberal hasta octubre de 1823. De nuevo se constituye en febrero de 1836 y ya permanece, con distintas modificaciones legislativas y constitucionales, hasta nuestros días. (Guía de archivos... 2006, p. 96).

\footnotetext{
${ }^{4}$ A.D.P.AL.: Libro de Actas de Sesiones Plenarias L-9.

${ }^{5}$ A.G.P.C.: Caja 4181.2 de mayo de 1820.
} 


\subsubsection{Diputación de Córdoba}

Sobre la Diputación de Córdoba, al igual que para otras corporaciones de carácter provincial, hay pocos estudios realizados con profundidad siendo, los más destacables, los realizados en los últimos tiempos por Martínez Hernández (2014), Espino Jiménez (2009) y Ventura Rojas (2008).

La documentación para el estudio de la creación de esta institución en el territorio cordobés la encontramos en el primer Libro de Actas que se inicia con el Acta de Instalación de la Diputación, el 18 de agosto de $1813^{6}$. El segundo intento de implantación lo encontramos en las actas del 2 de marzo de $1821^{7}$ y con la llegada al poder de Mendizábal se restablecen las diputaciones y su nueva andadura se inició entre el 14 de octubre y el 4 de noviembre de $1835^{8}$.

\subsubsection{Diputación de Granada}

Los primeros límites territoriales fueron establecidos con la creación de la provincia de Almería aunque, la segunda división organizada con el expediente de 1829 deja a Granada más definida y será el inicio de una nueva organización administrativa según lo expuesto por Cortés y Marina (1997, pp. 89-95).

A nivel institucional, la fecha del inicio de sesiones de la primera Diputación de Granada fue el 12 de mayo de $1813^{9}$ pero no sería hasta el 12 de abril de $1820^{10}$ cuando la Diputación diese cuenta al Rey de su nueva instalación. Tras numerosos avatares históricos, la reinstauración definitiva tuvo lugar el día 10 de octubre de $1836^{11}$.

\subsubsection{Diputación de Huelva}

Las primeras particiones administrativas de la actual provincia de Huelva, las encontramos en la división departamental ejecutada por la Real Orden de 19 de febrero de

\footnotetext{
${ }^{6}$ A.D.CO.: Libro de sus Actas y Sesiones desde el día 18 de Agosto de 1813 en que se instaló. HL 960.

${ }^{7}$ A.D.CO.: Libro 1o de Actas de la Diputación Provincial de Córdoba. Año de 1821. Principia el 2 de marzo y concluye el 28 de Mayo del mismo. HC 3763.3

${ }^{8}$ No se conserva el acta de instalación, pero el registro de correspondencia del Gobierno Civil acusa recibo de la normativa sobre creación de diputaciones el 14 de octubre de 1835, y el 4 de noviembre recibe una nota de la Diputación sobre el secretario de la misma. Entre ambas fechas debió constituirse (Martínez Hernández, 2014, p. 40).

${ }^{9}$ A.D.P.G.: Libro Copiador de oficios y órdenes no 2884, “Año de 1813, Día 12 de mayo de 1813, circular no 1 Instalación" fol. 1 r.

${ }^{10}$ A.D.P.G.: Libro Copiador de oficios, representaciones, consultas e informes a la superioridad no 2887 , "Restablecimiento de la Diputación Provincial de Granada con los mismos individuos que la formaban de el año de 1814, Año 1820", Día 12 de abril, Punto no 1 "A S.M. dando cuenta de haberse instalado la Diputación Provincial de Granada".

${ }^{11}$ A.D.P.G.: Libro, 1407 "Libro 1o de actas de la Diputación Provincial de Granada", fol. 1r "Instalación de la Diputación Provincial de Granada".
} 
1805 donde se aprobó la provincia de Sanlúcar de Barrameda, que incluía veintiocho pueblos (con sus respectivos términos), comprendidos en la franja costera entre el Guadiana y el Guadalquivir (Gozálvez y Rodríguez, 1980, p. 14). Posteriormente, José I Bonaparte realizó otra división de su territorio en dos subprefecturas; Aracena y Ayamonte, pertenecientes a la prefectura de Sevilla (Guaita, 1974, p. 316).

Todas estas traslocaciones territoriales han derivado en que la constitución de la diputación onubense no haya podido ser comprobada fehacientemente debido a la falta de fuentes documentales. Las primeras noticias de la formación definitiva de esta corporación datan del 16 de noviembre de 1835 y están recogidas en el primer Libro de Actas $^{12}$ de sesiones plenarias que fueron reproducidas por Rey y Sancha $(1995$, p. 74) en el catálogo documental sobre este organismo.

\subsubsection{Diputación de Jaén}

La primera referencia de la "provincia" de Jaén, la encontramos con la creación de la Provincia Marítima de Segura de la Sierra según lo citan Cruz Aguilar (1981, p. 53) y Montijano (2012, p. 837) y que quedaría suprimida el 22 de diciembre de 1833 con la aprobación de las Nuevas Ordenanzas de Montes (Chamocho, 2003, p. 79).

Las primeras noticias sobre la creación de la Diputación Provincial de Jaén las encontramos en el Archivo del municipio jienense de Rus donde se conserva el discurso pronunciado el 29 de junio de $1813^{13}$ por el presidente D. José Manuel de Vadillo con motivo de la primera constitución de la Corporación provincial. Sin embargo, la inestabilidad política de principios del siglo XIX hizo que esta nueva institución en Jaén no se consolidara hasta el 15 de noviembre de $1835^{14}$ cuando se reinstauraría la Diputación Provincial por tercera y última vez, manteniéndose hasta nuestros días.

\subsubsection{Diputación de Málaga}

Como referencia documental, cuando Juan Antonio Estrada escribe en 1746 Población General de España, sus Reynos y Provincias, villas, pueblos, islas adjacentes y Presidios de África, el nombre de Málaga no aparece como provincia, pues hasta el año 1801 el actual territorio estaba repartido entre los Reinos de Granada y Sevilla, que conjuntamente con los de Córdoba y Jaén formaban Andalucía.

Las fuentes escritas sobre la primera corporación provincial en Málaga hay que buscarlas en sus actas capitulares ${ }^{15}$ de 20 de diciembre de 1835, aunque queda oficialmente constituida el 20 de enero de 1836 según se publicó en el Boletín Oficial de la Provincia ${ }^{16}$.

\footnotetext{
${ }^{12}$ A.D.P.H.: Libro I, folios 1 al 6.

${ }^{13}$ A.M.Rus: Código 1.01.04.04, "Otras disposiciones (1784-1813)", caja 41.

${ }^{14}$ A.D.P.J.: Lib. A-1, Tomo 2, Fol 2R - 2V.

${ }^{15}$ A.M.M.: Actas Capitulares de 1835, volumen 234, folio 326 al 327v.
} 


\subsubsection{Diputación de Sevilla}

La referencia bibliográfica entorno al nacimiento de la Diputación sevillana la encontramos de la mano del profesor Cuenca Toribio (1963, pp. 211-212) quien nos relata como a finales de noviembre de $1813^{17}$ esta institución se da a conocer al Ayuntamiento mediante un oficio dirigido al Jefe Político.

\section{MÉTODO}

Abordamos el fenómeno de los "Días de la Provincia" a través de las circunstancias históricas que nos han llevado hasta la actualidad, avanzando hacia la comprensión de sus elementos y relaciones, mediante el análisis de su situación actual, pero también sus potencialidades de futuro. Desde esta perspectiva integradora, concebimos teoría e investigación como elementos que se complementan desde un punto de vista funcional: la documentación teórica no sólo nos ofrece un sistema conceptual de partida (la historia de estas instituciones que crea un signo identitario), incluyendo un sistema de clasificación y unificación sistemática que nos ordena la relación diputación-sociedad, sino que orienta nuestra investigación en cuanto que nos señala los hechos significativos que han de estudiarse y su importancia relativa.

Para el análisis de esta realidad recurrimos al estudio de casos puesto que el objetivo del método del caso es el mejor conocimiento de un aspecto sociológicamente relevante de la realidad. Con esta finalidad tenemos que realizar una acotación conceptual, espacial y temporal del objeto de estudio, que se ha precisado del siguiente modo:

1. Conceptual: la celebración del "Día de la Provincia" como base de una identidad común.

2. Espacial: nos hemos ceñido al ámbito de la Comunidad Autónoma andaluza que comprende ocho diputaciones provinciales: Almería, Cádiz, Córdoba, Granada, Huelva, Jaén, Málaga y Sevilla.

3. Temporal: desde 1998 (que es cuando aparecen la primera conmemoración del "Día de la Provincia" en Almería), hasta la actualidad (2018) por ser el periodo en el que se afianza la celebración de esta efeméride institucional.

En la actualidad, el estudio de los "Días de la Provincia" que se están instituyendo por toda nuestra geografía es un ejemplo de conmemoración de acontecimientos pasados que tienen una proyección hoy en día.

\footnotetext{
${ }^{16}$ A.D.P.M.: Boletín Oficial de la Provincia de Málaga no 719 de 26 de enero de 1836. (L-4792).

${ }^{17}$ A.M.S.: Sección 8aㅡ (1a Época Constitucional), Tomo V, número 42.
} 


\section{RESULTADOS}

Si bien la relación de actos que organiza una Diputación Provincial puede ser muy numerosos hemos querido traer aquí los que tienen una clara finalidad institucional: los "Día de la Provincia" que en cada una de las entidades supramunicipales tienen lugar en una fecha determinada, aunque todos con la misma vocación.

A pesar de las diferencias de organización interna de las Corporaciones provinciales, sí que es constatable el interés por buscar, en estos últimos años, una fecha concreta de conmemoración y que, a su vez, se celebre e identifique con el acto de entrega de galardones. De este modo, casi todas las Diputaciones tienen instaurado el Día de la Provincia de forma oficial u oficiosa.

En la Diputación de Almería, desde 1998, se estableció, como Día de la Provincia, el 15 de noviembre para conmemorar la declaración realizada el 15 de noviembre de 1835 por la reina Isabel II en la que se decretó la instalación de la Institución provincial ${ }^{18}$. Además, tal y como señala el reglamento se harán entrega de las distinciones en un acto solemne que se celebra cada año en un pueblo del territorio almeriense: Sorbas (1998), Zurgena (1999), Ohanes (2000), Rioja (2001), Gádor (2002), Vera (2003), Patio de las Luces de Diputación (2004), Berja (2005), El Ejido (2006), Albox (2007), María (2008), Aguadulce (2009) ${ }^{19}$, Patio de la Luces de la Diputación (2010), La Mojonera (2011) ${ }^{20}$, Macael (2012) ${ }^{21}$, Carboneras $(2013)^{22}$, Huércal-Overa $(2014)^{23}$, Adra $(2015)^{24}$, Níjar $(2016)^{25}$ y Roquetas de Mar $(2017)^{26}$. Con esta diversidad de sedes se refuerza la imagen de institución supramunicipal al servicio de los municipios que la componen.

El Día de la Provincia de Cádiz fue instituido el 19 de marzo de 1996 por el entonces presidente de Diputación, Rafael Román, quien convocó el primer acto solemne para

\footnotetext{
${ }^{18}$ http://blog.dipalme.org/diputacion-celebra-182-anos-la-entrega-las-medallas-la-provincia-parador/ (Consultado el 01/02/2018).

${ }^{19}$ http://www.diariodealmeria.es/cursos de verano/Medallas-celebrar-Diputacion-DiaProvincia 0 310468982.html (Consultado el 01/02/2018).

${ }^{20}$ http://www.diariodealmeria.es/almeria/Diputacion-entrega-mayores-distinciones-sobrio $0 \quad 537546316 . \mathrm{html}$ (Consultado el 01/02/2018).

${ }^{21}$ http://blog.dipalme.org/el-pleno-ratifica-a-macael-como-sede-del-dia-de-la-provincia-y-confirma-lasmedallas/ (Consultado 01/02/2018).

22 http://blog.dipalme.org/diputacion-entrega-sus-maximas-distinciones-en-el-dia-de-la-provincia/ (Consultado 01/02/2018)

${ }^{23} \mathrm{http} / / /$ blog.dipalme.org/huercal-overa-acoge-el-dia-de-la-provincia-y-la-entrega-de-medallas-de-diputacion/ (Consultado el 01/02/2018).

${ }^{24}$ http://blog.dipalme.org/diputacion-aprueba-las-medallas-del-dia-de-la-provincia-que-se-celebrara-en-adra/ (Consultado 01/02/2018).

${ }^{25}$ http://blog.dipalme.org/nijar-se-viste-de-gala-para-la-celebracion-del-dia-de-la-provincia-y-la-entrega-demedallas-de-diputacion/ (Consultado 01/02/2018).

${ }^{26}$ http://blog.dipalme.org/perez-siquier-victor-fernandez-los-puntos-salvamento-maritimo-candidatos-lasmedallas-la-provincia/ (Consultado el 01/02/2018).
} 
reconocer trayectorias ejemplares, con el ánimo de que la provincia de Cádiz fuera identificada con esos valores. Se eligió la citada fecha para asociarlo a las Cortes que, el 19 de marzo de 1812, promulgaron en Cádiz la primera Constitución española. La realización de este insigne acto institucional va cambiando su sede a lo largo de los años, de este modo se ha celebrado en los siguientes municipios: Cádiz (2008), Cádiz (2009) ${ }^{27}$, San Fernando (2010), Chiclana $(2011)^{28}$, Cádiz (2012) ${ }^{29}$, San Fernando $(2013)^{30}$, Jerez de la Frontera $(2014)^{31}$, Cádiz $(2015)^{32}$, Cádiz (2016) ${ }^{33}$ y Cádiz $(2017)^{34}$.

La Diputación cordobesa estableció en el año 2017 la primera convocatoria de los galardones del "Día de la Provincia" cuya convocatoria fue publicada en el Boletín Oficial de la Provincia de Córdoba ${ }^{35}$. Estos galardones se entregaron el 10 de noviembre ${ }^{36}$ en el marco de la Feria de los Municipios ${ }^{37}$ y coincidiendo con la conmemoración del día dedicado a la provincia de Córdoba $^{38}$. La continuidad de esta iniciativa depende, en este caso, de las aprobaciones presupuestarias correspondientes tal y como se deduce de la base segunda de la convocatoria por la que se rigen y que, a día de hoy, está en vigor.

Por parte de la Diputación de Granada ${ }^{39}$ el día de entrega de los galardones no es oficial pero sí oficioso celebrándolo a mediados de diciembre tal y como se desprende de las informaciones relativas a este tema que se publican anualmente en su página web, sobre

${ }^{27}$ http://aytochipiona.es/masnoticias.php?codigo=119 (Consultado 05/02/2018).

${ }^{28} \mathrm{http}: / /$ www.diariodecadiz.es/provincia/Medallas-honores-gaditanos-comprometidosprovincia 0 461654222.html (Consultado 05/02/2018).

${ }^{29}$ http://web.espera.es/prensa/historico/Cdiz-recibir-la-Medalla-de-la-Provincia-00001/ 05/02/2018).

${ }^{30} \mathrm{http} / / /$ www.dipucadiz.es/prensa/historico/Hijo-predilecto-y-medallas-del-Da-de-la-Provincia/ (Consultado el 05/02/2018).

${ }^{31}$ http://www.dipucadiz.es/prensa/actualidad/Aprobada-la-relacion-de-personas-y-entidades-que-serandistinguidas-el-19-de-marzo/ (Consultado 05/02/2018).

${ }^{32}$ http://www.dipucadiz.es/prensa/actualidad/Acto-solemne-y-entrega-de-distinciones-a-personas-yentidades-gaditanas-en-el-Teatro-Falla/ (Consultado 05/02/2018).

${ }^{33}$ http://www.dipucadiz.es/prensa/actualidad/El-Pleno-aprueba-la-distinciones-del-Dia-de-la-Provincia-deCadiz/ (Consultado 05/02/2018).

${ }^{34}$ http://www.dipucadiz.es/prensa/actualidad/Entregadas-las-distinciones-del-Dia-de-la-Provincia-de-Cadiz/ (Consultado el 05/02/2018).

${ }^{35}$ Boletín Oficial de la Provincia de Córdoba no 168, de 4 de septiembre de 2017.

${ }^{36}$ Diputación de Córdoba (10 de noviembre de 2017). En este enlace podéis ver y descargar todas las fotos de la I Gala del Día de la Provincia [Tuit]. Recuperado de https://twitter.com/dipucordoba/status/929109661848100866

${ }^{37}$ Diputación de Córdoba (9 de noviembre de 2017). Mañana a las 20:30 horas celebramos los I Galardones de la Provincia en el marco de la \#FMunicipiosCOR [Tuit]. Recuperado de https://twitter.com/dipucordoba/status/928669880940941312

38 https://www.dipucordoba.es/dipucordoba/contenidos/52412/diputacion-convoca-los-i-galardones-del-diade-la-provincia-para-reconocer-el-trabajo-de-colectivos-y-asociaciones-provinciales?tab=\&text=galardones (Consultado el 09/02/2018).

${ }^{39}$ http://www.dipgra.es/amplia-actualidad/cultura/poeta-antonio-carvajal-gestor-cultural-alfonso-alcala-hijospredilecto-adoptivo-provincia (Consultado el 09/02/2018). 
todo de los actos de entrega de honores y distinciones que es el acto institucional principal que se celebra ese día.

En cuanto a la Diputación de Huelva ${ }^{40}$ celebra el "Día de la Provincia" a mediados del mes de noviembre $y$, al igual que otras corporaciones provinciales, procura unir esta conmemoración con la entrega de galardones honoríficos. Si bien los primeros años se realizó en la ciudad de Huelva, en años sucesivos se ha procurado realizar en algunos pueblos de su territorio: Huelva $(2008)^{41}$, Huelva $(2009)^{42}$, Huelva $(2010)^{43}$, Huelva $(2011)^{44}$, Aracena $(2012)^{45}$, Punta Umbría $(2013)^{46}$, Nerva $(2014)^{47}$, Almonte $(2015)^{48}$, Foro Iberoamericano $(2016)^{49}$ y Punta Umbría $(2017)^{50}$.

La Diputación de Jaén decretó en 2015 la creación del Día de la Provincia ${ }^{51}$ en la fecha del 19 de marzo y, desde ese momento, va unida esta efeméride con la celebración de la "Feria de los Pueblos". Del mismo modo se aprovecha estos acontecimientos para la entrega de los galardones "Premios de la Provincia" ${ }^{52}$ que se ha celebrado en tres ediciones: $2015^{53}, 2016^{54}$ y $2017^{55}$.

Sin embargo, la Diputación de Málaga ${ }^{56}$ sí que tiene institucionalizada la entrega de estos galardones dentro de la celebración del Día de la Provincia ${ }^{57}$. La creación de esta

\footnotetext{
${ }^{40}$ http://www.diphuelva.es/noticias/10086 unanimidad-en-el-pleno-de-las-medallas $\quad$ (Consultado el 15/02/2018)

${ }^{41}$ http://www.diariocordoba.com/noticias/cordobaandalucia/juan-jose-cortes-medalla-orohuelva 444726.html (Consultado 15/02/2018).

${ }^{42}$ http://www.europapress.es/andalucia/huelva-00354/noticia-diputacion-concede-medallas-oro-cientificoperez-mercarder-empresarios-turisticos-hermanas-cruz-20091103133642.html (Consultado 15/02/2018).

${ }^{43}$ http://www.europapress.es/andalucia/huelva-00354/noticia-diputacion-entrega-jueves-medallas-oro-jesusquintero-litri-ence-20101110162227.html (Consultado 15/02/2018).

${ }^{44}$ http://huelvaya.es/2011/11/11/diputacion-entrega-las-medallas-de-la-provincia/ (Consultado 15/02/2018).

45 http://www.diphuelva.es/b/galerias/2138 medallas-provincia-2012 (Consultado 15/02/2018).

${ }^{46}$ http://www.diphuelva.es/b/noticias/3381 el-pleno-de-la-diputacion-respalda-unani $15 / 02 / 2018)$

${ }^{47}$ https://www.youtube.com/watch?v=y7U3mETnruE (Consultado 15/02/2018).

${ }^{48} \mathrm{http}: / / w w w . d i p h u e l v a . e s / n o t i c i a s / 6644$ pleno-concesion-medallas-de-la-provincia-2015 $\quad$ (Consultado 15/02/2018).

${ }^{49}$ http://www.diphuelva.es/b/noticias/8195 unanimidad-concesion-medallas-de-la-provincia-2016 (Consultado el 15/02/2018).

${ }^{50}$ https://www.youtube.com/watch?v=dPFIKQHatvE (Consultado 15/02/2018).

${ }^{51}$ https://www.dipujaen.es/ area-de-actualidad/detalles.html?uid=3f304484-1e1e-11e8-8ac0-005056b0675f (Consultado el 17/02/2018).

${ }^{52}$ https://www.dipujaen.es/conoce-diputacion/areas-organismosempresas/areaA/premios provincia jaen.html (Consultado 17/02/2018).

${ }^{53}$ https://www.youtube.com/watch?v=d5T6IfGZ-14 (Consultado 17/02/2018).

54 https://www.youtube.com/watch?v=vJNIXIRe-mA (Consultado 17/02/2018).

55 https://www.youtube.com/watch?v=b226GEcb-W4 (Consultado 17/02/2018).

56 http://www.malaga.es/diputacion/117/conmemoraciones (Consultado el 26/02/2018).

57 http://www.malaga.es//diputacion/117/instauracion-provincia (Consultado el 26/02/2018).
} 
efeméride fue acordada por el Pleno de la Diputación Provincial celebrada el 16 de marzo de 2004 para que se realizara cada 26 de abril, ya que en esa fecha del año 1979 se constituyó la primera corporación democrática. Este día contendría un acto oficial donde, además de una Declaración Institucional, se premiaría y distinguiría el trabajo de distintas personalidades de Málaga que han destacado en su campo o actividad profesional. Desde su instauración, este acto se ha ido organizando en distintos ayuntamientos de la provincia: Antequera $(2004)^{58}$, Álora $(2005)^{59}$, Mijas (2006) ${ }^{60}$, Vélez-Málaga (2007) ${ }^{61}$, Málaga (2008) ${ }^{62}$, Ronda $(2009)^{63}$, Archidona $(2010)^{64}$, Cártama $(2011)^{65}$, Nerja $(2012)^{66}$, Casares $(2013)^{67}$, Macharaviaya $(2014)^{68}$, Estepona $(2015)^{69}$, Antequera $(2016)^{70}$ y Torremolinos $(2017)^{71}$.

Por último, la Diputación de Sevilla ${ }^{72}$ también tiene designado el Día de la Provincia ${ }^{73}$ que se celebra cada 23 de mayo, fecha que fue elegida en recuerdo de un hecho histórico: la aparición de la provincia como demarcación territorial de España a partir de la Constitución de Cádiz de 1812 recogidas en el decreto que tenía fecha de 23 de mayo de 1812. Desde 2005 que fue cuando se estableció mediante el artículo 11 del reglamento de honores y distinciones publicado en el Boletín Oficial de la Provincia no 24 de 31 de enero de $2006^{74}$, ha sido la fecha elegida para la entrega de los honores y distinciones.

Como hemos visto, la conmemoración del "Día de la Provincia", si bien se ha celebrado con anterioridad aunque de forma esporádica, está motivada y definida en relación con la misión, visión y valores que la administración quiere difundir entre sus ciudadanos sentando las bases del modelo de sociedad que se quiere construir y promoviendo las áreas de actuación de los entes sociales que son dignos de elogio.

En todos los casos de estudio, las Corporaciones provinciales buscan que se produzca una identificación entre la festividad del "Día de la Provincia" con la entrega de galardones y, para lograrlo, necesitan de unos departamentos que ejecuten estos actos para reforzar una

\footnotetext{
${ }^{58}$ http://www.malaga.es//diputacion/122/primer-provincia-antequera-abril-2004 (Consultado 26/02/2018).

59 http://www.malaga.es//diputacion/123/provincia-alora-abril-2005 (Consultado 26/02/2018).

60 http://www.malaga.es//diputacion/124/provincia-mijas-abril-2006 (Consultado 26/02/2018).

61 http://www.malaga.es//diputacion/125/provincia-velez-malaga-abril-2007 (Consultado 26/02/2018).

62 http://www.malaga.es//diputacion/127/provincia-malaga-abril-2008 (Consultado 26/02/2018).

63 http://www.malaga.es//diputacion/128/provincia-ronda-abril-2009 (Consultado 26/02/2018).

64 http://www.malaga.es//diputacion/506/provincia-archidona-abril-2010 (Consultado 26/02/2018).

65 http://www.malaga.es//diputacion/2522/viii-provincia-cartama-abril-2011 (Consultado 26/02/2018).

66 http://www.malaga.es//diputacion/6113/provincia-nerja-abril-2012 (Consultado 26/02/2018).

67 http://www.malaga.es//diputacion/6115/provincia-casares-abril-2013 (Consultado 26/02/2018).

68 http://www.malaga.es//diputacion/6116/provincia-macharaviaya-abril-2014 (Consultado 26/02/2018).

69 http://www.malaga.es//diputacion/6117/provincia-estepona-abril-2015 (Consultado 26/02/2018).

70 http://www.malaga.es/diputacion/6118/xiii-provincia-antequera-abril-2016 (Consultado 26/02/2018).

71 http://www.malaga.es/base/descargas/home.asp?cod=271418 (Consultado 26/02/2018).

72 http://diadelaprovincia.dipusevilla.es/ (Consultado 26/02/2018).

${ }^{73}$ http://diadelaprovincia.dipusevilla.es/diadelaprovincia2017/ elementos/introduccion-ampliada.html (Consultado 26/02/2018).

${ }^{74}$ http://www.dipusevilla.es/bop/ (Consultado 26/02/2018).
} 
política de Relaciones Institucionales de largo recorrido donde se proyecte la identidad local mediante los actos institucionales y de la que se haga partícipes a la ciudadanía.

\section{DISCUSIÓN}

Los resultados expuestos a través de esta investigación nos revelan una consolidación en la conmemoración de estas fechas como eje de la comunicación organizacional entre la administración y la sociedad a la que pertenece.

La realidad histórica sobrevenida con la creación de las diputaciones provinciales en el territorio de Andalucía es, en la actualidad, una de las bases de la administración política y parte de nuestro acervo institucional. Y la política de comunicación de estos actos conmemorativos se realiza mediante las plataformas existentes en internet y las redes sociales tal y como se recoge en la mayor parte de la información complementaria de esta investigación que está soportada en fuentes digitales; páginas webs de los distintos organismos, perfiles oficiales en redes sociales como twitter, youtube fundamentalmente, blogs corporativos y periódicos digitales que nos demuestran que el proceso de investigación actualmente pasa inexorablemente a través de los medios digitales. Bien a través de portales específicos, como por ejemplo disponen las diputaciones de Málaga y Sevilla, o mediante noticias en la sección de "Actualidad", el medio digital se ha convertido en los últimos años en el eje central del flujo de información entre las instituciones políticas y la sociedad sobre la que ejerce su labor.

Sin embargo, a pesar de toda esta cantidad de información digital no existen valoraciones, por parte de las corporaciones provinciales, que indiquen el alcance que tienen las noticias relativas a la celebración del "Día de la Provincia" para su reputación organizacional e imagen institucional. Sería conveniente el establecimiento de grupos de investigación transversales por parte de los departamentos universitarios que, ejerciendo una labor como asesores externos de las entidades locales, pudiesen elaborar informes o memorias que se ciñan a esta o cualquier otra actividad.

Tenemos que conocer nuestro pasado para tener criterios de análisis de las relaciones institucionales del momento presente y poder mejorar el futuro de la realización de estas conmemoraciones provinciales.

\section{REFERENCIAS}

BURGEÑO, J. (1995): "De los cuatros reinos a las ocho provincias" en Cuadernos Geográficos no $24-25$. Págs.: $33-49$.

CHAMOCHO CANTUDO, M.A. (2003): Jaén, de Reino a Provincia: la gestación de la provincia y su territorio en el siglo XIX. Jaén. Instituto de Estudios Giennenses. 
CORTÉS PEÑA, A.L. y MARINA BARBA, J. (1997): Proyectos de división territorial en la crisis del Antiguo Régimen. Granada, de reino a provincia. Granada. Centro de Estudios Municipales y Cooperación Internacional (CEMCI).

CRUZ AGUILAR, E. (1981): "La provincia marítima de Segura de la Sierra" en Boletín de Estudios Giennenses no 107. Págs.: 51 - 82.

CUENCA TORIBIO, J. M. (1963): "Los orígenes de la Diputación sevillana" en Revista Archivo Hispalense, no 118, Tomo XXXVIII. Págs.: $209-212$.

ESPINO JIMÉNEZ, F.M. (2009): Administración territorial y centralismo en la España Liberal. La Diputación de Córdoba durante el reinado de Isabel II (1843-1868). Córdoba, Diputación de Córdoba, Departamento de ediciones y publicaciones.

GONZÁLEZ CASANOVAS, J.A. (1986): Las Diputaciones Provinciales en España. Madrid. Mancomunidad General de Diputaciones de Régimen Común.

GOZÁLVEZ ESCOBAR, J.L.; RODRÍGUEZ CRIADO, I. (1980): Huelva del Antiguo al Nuevo Régimen: la constitución del territorio provincial y su capitalidad. Revista EREBEA $n$ o 2 (Tirada Aparte). Huelva, Colegio Universitario de La Rábida.

GUAITA, A. (1974): "La división provincial y sus modificaciones" en III Symposium de Historia de la Administración. Madrid, Instituto de Estudios Administrativos.

Guía de archivos de las Diputaciones Provinciales y Forales y de los Consejos y Cabildos Insulares de España (2006). Cádiz, Diputación Provincial de Cádiz.

MARTíNEZ DÍEZ, G. (1981): "Génesis histórica de las provincias españolas" en Anuario de historia del derecho no 51, págs.: 523-593.

MARTÍNEZ HERNÁNDEZ, M.C. (2014): Imágenes para la historia de la Diputación de Córdoba (1813 - 1983). Córdoba. Diputación de Córdoba, Departamento de Archivo.

MONTIJANO FUENTES, J.M. (2012): "La provincia marítima de Segura de la Sierra. Una dependencia de la Armada en el interior" en Revista General de la Marina Tomo 263. Págs.: 832-842

OJEDA RIVERA, J. F. (1986): "Los efectos de la provincialización en el triángulo Huelva-SevillaCádiz", en Revista de Estudios Andaluces no 7, págs..: 147 - 164.

REY DE LAS PEÑAS, R. y SANCHA SORIA, F. (1995): El tiempo y las fuentes de su memoria. Historia Moderna y Contemporánea de la provincia de Huelva. Tomo I: Catálogo Documental. Huelva, Diputación Provincial de Huelva, Servicio de Archivo. 
SANJUÁN ANDRÉS, F.J (2012): "Las Diputaciones Provinciales. Una aproximación a los orígenes de la Diputación de Cádiz” en Historia Constitucional no 13. Págs.: 271 -282.

SANTANA MOLINA, M. (1989): La Diputación Provincial en la España decimonónica. Madrid, Instituto Nacional de Administración Pública.

VENTURA ROJAS, J.M. (2008): La provincia de Córdoba durante el reinado de Fernando VII (1808-1833): el marco socioeconómico. Madrid, Fundación Universitaria Española.

(c) (1) $]_{\text {This work is licensed under a }}$ 